\title{
Anxiety and Ironic Errors of Performance: Task Instruction Matters
}

Gorgulu, Recep; Cooke, Andrew; Woodman, Tim

\section{Journal of Sport and Exercise Psychology}

\author{
DOI: \\ 10.1123/jsep.2018-0268 \\ Published: 01/04/2019 \\ Peer reviewed version \\ Cyswllt i'r cyhoeddiad / Link to publication
}

Dyfyniad o'r fersiwn a gyhoeddwyd / Citation for published version (APA):

Gorgulu, R., Cooke, A., \& Woodman, T. (2019). Anxiety and Ironic Errors of Performance: Task Instruction Matters. Journal of Sport and Exercise Psychology, 41(2), 82-95.

https://doi.org/10.1123/jsep.2018-0268

\footnotetext{
Hawliau Cyffredinol / General rights

Copyright and moral rights for the publications made accessible in the public portal are retained by the authors and/or other copyright owners and it is a condition of accessing publications that users recognise and abide by the legal requirements associated with these rights.

- Users may download and print one copy of any publication from the public portal for the purpose of private study or research.

- You may not further distribute the material or use it for any profit-making activity or commercial gain

- You may freely distribute the URL identifying the publication in the public portal ?
}

Take down policy

If you believe that this document breaches copyright please contact us providing details, and we will remove access to the work immediately and investigate your claim. 
2

3

4 Date of re-submission: 08.02.2019

$5 \quad$ Word count: 9.432

6

7

8

9

10

11

12

13

14

15

16

17

18

19

20

21

22

23

24

25 
Abstract

We present five experiments that examined Wegner's (1994) theory of ironic

processes of mental control in reactive motor performance under pressure for the first time. In

29 Experiments 1, 2 and 4, we conducted specific examinations of the incidence of ironic error

30 using a reactive motor task. In Experiments 3 and 5 we provided the first tests of whether

31 task instruction moderates the incidence of ironic errors. The task required participants to

32 react to a series of three primary color balls as they rolled down a chute under low- and high-

33 anxiety conditions. Measures of anxiety, heart rate, heart rate variability and muscle activity

34 confirmed the effectiveness of the anxiety manipulation. Experiments 1,2 and 4 revealed that

35 anxiety increased the number of ironic errors. In Experiments 3 and 5, we provided the first

36 evidence that instructional interventions can reduce the incidence of anxiety-induced ironic

37 performance errors in reactive motor tasks.

$38 \quad$ Keywords: Anxiety, ironic error, reactive task, instruction. 


\section{Anxiety and Ironic Errors of Performance: Task instruction matters.}

The influence of anxiety on motor performance is central to performance psychology (e.g., Woodman \& Hardy, 2003). An extensive body of research devoted to determining the nature of the anxiety-performance relationship has investigated theories such as the conscious processing hypothesis (Masters, 1992), attentional control theory (Eysenck, Derakshan, Santos, \& Calvo, 2007), and catastrophe models (Hardy, Woodman, \& Carrington, 2004). However, these theories do not offer a mechanism via which anxiety can elicit precisely counter-intentional errors. These errors are more severe than general errors, and represent the worse possible scenario; that is, making the mistake one least wants to make (Janelle, 1999). For example, a professional soccer player might instruct herself to avoid striking her penalty wide of the post, before proceeding to do exactly that. One can explain such counterintentional errors through Wegner's (1994) theory of ironic processes of mental control. To date this theory has received comparatively scant attention in the anxiety and motor performance literature. This is surprising when one considers that the consequences of counter-intentional errors in the motor performance domain, especially during tasks that require rapid decisions and responses to ever-changing environmental stimuli (e.g., competitive sport, emergency services, and armed forces) can be severe. Indeed, we are aware of no study applying ironic processes theory to the anxiety and performance relationship, where the performance task is reactive in nature. We designed the experiments in this manuscript to be the first to examine Wegner's theory of ironic processes of mental control as an explanation for anxiety-induced counter-intentional errors during reactive motor performance.

\section{Ironic Processes of Mental Control}

The foundation to Wegner's (1994,) theory is that so-called operating and monitoring cognitive processes work together to produce our thoughts and actions. Specifically, an 
intentional operating process carries out effortful regulation by consciously searching for, and directing the person toward, mental contents that will yield an intended emotional state or preferred outcome. Meanwhile an ironic monitoring process subconsciously searches for signals of failure to achieve the desired state; the monitoring process is unconscious, autonomous, and less demanding of mental effort. If this subconscious monitor identifies any such failures then it reactivates the intentional operating process, which aims to bring about the regulation by filling the mind with mental contents that are consistent with the desired state.

Under normal circumstances, both processes work within one control system and operate together as part of a feedback loop that provides effective mental control for the individual (Wegner, 1994). However, under conditions where there is competition for resources within our limited attentional capacity, such as when anxiety increases and burdens our conscious attention with worrisome thoughts, there is limited cognitive space for the effortful operating process to work effectively. Conversely, the functionality of the monitoring process remains mainly unaffected due to its unconscious and uninterruptable feature (i.e., once they materialize, they cannot be stopped), which yields a search for components related to the failure of the intended state of mind or behavior. Due to this diminishing effectiveness of the operating process, the monitoring process becomes relatively more prevalent with increasing anxiety. More specifically, when the monitoring process carries out a sweep for information on the to-be-avoided outcome (e.g., missing a kick to the left of the post), it brings that very scenario into consciousness. If there is insufficient capacity to re-engage the effortful operating process (e.g., when cognitive load, such as anxiety, increases), this precisely counter-intentional error ensues (Wegner, 1994). Consequently, the ironic monitoring process becomes more salient, and mental control 
paradoxically starts working against itself by attending to those unwanted thoughts (Janelle, 1999).

\section{Ironic Effects and Motor Performance: Existing Research}

Wegner, Ansfield and Pilloff (1998) provided some seminal evidence to support Wegner's (1994) theory as an explanation for counter-intentional errors in the motor performance domain. In one study, participants were asked to avoid moving a hand-held pendulum along a particular axis (or simply to hold it steady without mention of a direction), and in a second study they were asked not to hit golf ball past the glow spot. Consistent with ironic processes of mental control theory, participants under mental (working memory) load made more counter intentional-errors than those who were under no such load.

Others have reported similar effects . For example, Dugdale and Eklund (2003) investigated the incidence of ironic effects in a well-learnt wobble board task. Skilled dancers were required to balance on a wobble board for twenty seconds. Results revealed that participants were less stable on the wobble board during trials where they were instructed "don't wobble" compared to trials where they were instructued to "hold steady". Further, in a dart throwing task, Oudejans, Binsch, and Bakker (2013) demonstrated that the combination of negatively woded instructions (''Be careful not to hit....') and induced anxiety significantly increased the number of darts landing in the specifically to-be-avoided zone when compared to negatively worded instructions under low -anxiety conditions.

Woodman, Barlow and Gorgulu (2015) also conducted experiments using a dart board, which they divided into a central target (i.e., bull's-eye) and four equally sized quadrants that extended out from the bulls-eye to the edge of the board. Participants were instructed to aim for the bulls-eye while being particularly careful not to hit one of the the four quadrants (e.g., top-right zone). Results revealed that performance deteriorated from low- to high-anxiety conditions, and was characterized by an anxiety-induced increase in the 
114 number of darts landing in the specifically to-be-avoided zone. Extending this work, Barlow,

115 Woodman, Gorgulu and Voyzey (2016) revealed that trait neutroticism moderates the

116 incidence of ironic errors during high-anxiety conditions. Individuals scoring relatively high

117 in neuroticism made more ironic errors than those who were relatively low in neutroticism

118 during football penalty shooting and dart throwing tasks. Finally, Gray, Orn and Woodman

119 (2017) revealed that experienced baseball pitchers displayed an anxiety-induced increase in

120 the number of balls pitched to an ironic (avoid) zone, while the kinematics of their technique

121 remained stable. This finding supports an ironic processes account of performance

122 breakdown over the explanations offered by self-focus theories (e.g., conscious processing

123 hypothesis; Masters, 1992), since self-focus theories predict that experienced performers

124 break down under anxiety by regressing to a more novice-like technique. Taken together

125 these findings provide encouraging support for Wegner's (1994) ironic processes theory as an

126 explanation for counter-intentional errors, including those that occur under anxiety, in motor

127 performance.

128 Two main shortcomings remain in the limited research to date. First, previous anxiety

129 and ironic effects research has considered only self-paced aiming movements, which

130 arguably comprise a limited portion of daily activities for the majority of people. Making

131 decisions and responses based on ever-changing stimuli in our environment occupies an

132 arguably larger portion of day-to-day life (Gorgulu, 2017). Moreover, time pressures inherent

133 in reactive tasks likely present an additional load (e.g., Wegner \& Erber, 1992) that is absent

134 from self-paced tasks, and which could increase the likelihood of ironic errors in reactive

135 situations. Accordingly, research designed to scrutinize the predictions of ironic processes

136 theory in anxiety-laden reactive tasks is clearly warranted. Such research could encourage

137 coaches and psychologists to carefully consider ironic effects in addition to other more well-

138 known theories (e.g., attentional control theory; conscious processing hypothesis) when 
designing interventions to prevent any adverse effects of anxiety on the performance of their

140 athletes. Currently, there is no test of ironic processes theory in reactive, externally paced 141 contexts.

142 Second, while recent research has identified conditions that might promote ironic

143 effects (e.g., Barlow, Woodman, Gorgulu, \& Voyzey, 2016; Gray, Orn, \& Woodman, 2017),

144 there has been no research dedicated to interventions aimed at reducing the incidence of

145 ironic errors. From a theoretical perspective, one method of reducing the likelihood of ironic

146 effects could be manipulating task instructions to ensure that the monitoring process is

147 searching for features that are more difficult to find than those sought by the operator

148 (Wegner, 1994). This could be especially effective in time-limited reactive motor tasks,

149 where one often faces the choice of either making a reactive movement or doing nothing. For

150 example, a cricket batsman has to decide whether to play a shot (i.e., an action) or to leave

151 the ball (i.e., an inaction), and against pace bowlers who deliver balls at speeds in excess of

$15280 \mathrm{mph}$, if this decision is not made in less than $500 \mathrm{~ms}$ then inaction is the default outcome

153 (Land \& McLeod, 2000). Both action and inaction options in this example could require

154 varying levels of stimulus detection and stimulus identification stages of information

155 processing, but playing a shot would require an additional stage of response programming in

156 order to bring that behavior to fruition (Schmidt, 1980). Accordingly, one could argue that

157 playing a shot (i.e., action) represents a more cognitively demanding and time-consuming

158 process than leaving the ball (i.e., inaction). Thus, instructions tailored to burden the

159 monitoring process with a search for features consistent with actions rather than inactions

160 might help to reduce the likelihood of the monitor coming to the fore. Our experiments will

161 test this theoretically-driven prediction. Importantly, if the predictions are supported, this

162 body of research will provide the first framework for athletes, coaches and psychologists for

163 using instructional interventions to mitigate ironic errors during reactive sports. 

provide the first examination of ironic effects theory in an externally paced task under lowand high-anxiety conditions. We hypothesized that reactive motor performance would suffer in a specifically ironic fashion when performers were anxious. Experiment 3 provides the

169 first test of whether task instruction moderates the likelihood of ironic errors. We

170 hypothesized fewer ironic errors under high-anxiety conditions when we tailored instructions to load the monitoring process with a more difficult action-based search compared to inaction-based search. Experiments 4 and 5 replicate Experiments 2 and 3, but with a slightly modified manipulation designed to offer an even more rigorous test of the predictions cited

174 above.

\section{Experiment 1}

In Experiment 1, we aimed to create an approximate externally paced analog of

177 Wegner's (1998) classic pendulum experiments. Specifically, we asked participants to react to two different colored balls as they rolled down a chute, a target (e.g., red) that was to be caught, and a non-target (e.g., blue) that was to be avoided. If Wegner's theory of ironic

180 processes of mental control holds for externally paced tasks, we expected participants in a high-anxiety condition to catch more non-target balls (i.e., make more to-be-avoided errors) than in a low-anxiety condition.

Method

Participants. The sample comprised 53 individuals (32 men, 21 women; $M_{\text {age }}=$ 19.62, $S D=2.09 ; 47$ right handed, 6 left handed). We recruited participants on a volunteer basis through advertisement posters. All participants reported being free from illness and injury at the time of the experiment. We obtained informed consent from all participants over 
188 the course of the Experiment 1 to Experiment 5. All the experiments (Experiments 1-5) were

189 approved by the University research ethics committee.

190 The GPower 3.1 (Faul, Erdfelder, Buchner, \& Lang, 2013) calculation software

191 indicated that by adopting an alpha of .05 and a sample size of 53 the experiment was

192 powered at .80 to detect significant differences between conditions for effect sizes exceeding

$193 f=.20$ (i.e., small-to-medium size effects), by repeated measures analysis of variance (Cohen,

194 1992). While there are limited previous data upon which to base these calculations,

195 Woodman et al.'s (2015) test of ironic effects, adopting a similar design, revealed large

196 within-subject effects $\left(\eta_{\mathrm{p}}{ }^{2} \mathrm{~s}=.25\right)$. Accordingly, if similar effects were to emerge, the

197 samples we recruited in each of Experiment 1 through to Experiment 5 were more than

198 adequately powered to detect them.

199 Design and Task. We adopted a within-subject design; all participants completed a reactive motor task under both low- and high-anxiety conditions. Participants sat adjacent to the bottom end of a $174 \mathrm{~cm}$ length black chute, raised $58 \mathrm{~cm}$ above the ground at the lower end, and set at a gradient of 27 degrees (Figure 1). Their task was to react to a series of red and blue balls as each ball rolled down the chute. Specifically, using a table tennis bat held in their dominant hand, participants either stopped the ball (i.e., they held the bat firm against the end of the chute) or they allowed the ball to continue its trajectory off the end of the chute to the ground (i.e., they moved the bat away from the chute end). Before commencing each condition we told participants, "every ball you stop will go into a prize bucket, the red ball will score you plus five points and the blue ball will score you minus five points. Obviously, you should be very careful not to stop the blue balls! Please try to score as many points as 210 possible."

211 We secured a wooden board partition to the rear end of the chute in order to prevent

212 participants from seeing the color of the ball before it entered the chute. We concealed the top 
$21392 \mathrm{~cm}$ of the chute to allow for an appropriate choice response time $(450 \mathrm{~ms})$ on seeing the ball

214 and its color. We determined this response time via pilot testing, which indicated that this

215 time ensured that participants had enough time to respond to ball color, but not so much as to

216 make the task easy. This response time is consistent with response times observed in previous

217 studies using similar choice-based tasks (Miller \& Low, 2001).

218 Our task and instructions established a target ball and a non-target ball. In the above

219 example, the target ball is red, and the non-target ball is blue. The instructions were modified

220 between participants to ensure that each ball color had an equal turn at being the target and

221 the non-target ball over the course of the experiment (i.e., fully counterbalanced). Participants

222 responded to 30 balls (15 blue and 15 red) in both low-anxiety and high-anxiety conditions.

223 Details of the anxiety manipulation are in the Procedure section below.

** INSERT FIGURE 1 ABOUT HERE **

\section{Measures}

Anxiety. Anxiety was measured using the Mental Readiness Form-3 (MRF-3; Krane, 1994). Participants were asked to express how they felt right now by responding to three 11point Likert-type scales. From left to right the scales are anchored at extremes with not worried and worried for cognitive anxiety; and not tense and tense for somatic anxiety. Thus, high scores represent high cognitive anxiety, and high somatic anxiety, respectively. The MRF-3 is commonly used in anxiety and motor performance research (e.g., Barlow et al., 2016; Robazza, Bortoli, \& Nougier, 2000; Woodman \& Davis, 2008; Woodman et al., 2015). psychophysiological indices of anxiety. We measured heart rate and heart rate variability via electrocardiogram (ECG). We placed disposable silver/silver chloride electrodes (Blue sensor, Ambu, St Ives, UK) on the right and left clavicals and on the lowest left rib. An amplifier (Dual BioAmp, ADInstruments, Oxford, UK) connected to a 16-bit digital-to- 
analog convertor (Powerlab, ADInstruments) and a computer running Chart 7 software (Chart

v7.3.7, ADInstruments), were used to acquire the ECG signals. Recordings were

subsequently imported into Kubios HRV version 2.2 software (Tarvainen, Niskanen,

241 Lipponen, Ranta-aho \& Karjalainen, 2014) for offline analyses. Specifically, we computed

242 heart rate (beats per minute) as well as the root mean square of successive R-R intervals (r-

243 MSSD), as a time-domain measure of heart rate variability. We chose these measures because

244 increased heart rate and decreased r-MSSD have previously been associated with elevated

245 pre-competitive anxiety (e.g., Barlow et al., 2016; Mateo et al., 2011; Murray \& Raedeke, 246 2008).

Muscle activity. As an additional objective measure of arousal and tension associated

with anxiety, we recorded muscle activity in the dominant forearm. We placed two silver/silver chloride electrodes (Neuroline 720, Ambu, St Ives, UK) $2 \mathrm{~mm}$ apart, over the belly of the extensor carpi radialis muscle, and a reference electrode (Blue sensor, Ambu, St Ives, UK) on the left clavicle. The signal was amplified (Dual BioAmp, ADInstruments, Oxford, UK), filtered (50-500 Hz) and then processed at a sample rate of $1000 \mathrm{~Hz}$ by a 16-bit PowerLab data acquisition system (ADInstruments, Oxford, UK) connected to a computer running Chart 7 software (ADInstruments, Oxford, UK). We chose the extensor carpi radialis based on pilot testing and previous research implicating this muscle in anxiety-induced increases in grip force during motor tasks (e.g., Cooke et al., 2010; Smith et al., 2000). target balls that were stopped in each condition. An electronic buzzer system was connected to the lower end of the apparatus to allow us to determine clearly whether a ball was successfully stopped. The start position for each trial required participants to hold the bat

261 flushes to the end of the chute. This depressed the buzzer switch and ensured that the buzzer 
263 the switch and caused the buzzer to sound. Participants were told that the buzzer had to

264 remain silent for a stop to be deemed successful. This criterion prevented participants from

265 making multiple bat movements, such as initially moving the bat away from the end of the

266 chute, and then returning it in time to stop the ball. The range of scores was 0-15 for each

267 ball, where the best score would be 15 for the target balls, and 0 for the non-target balls.

268 Procedure. Each participant individually attended a single laboratory session lasting

269 approximately 60 minutes. Upon entry to the laboratory, we first briefed participants about

270 the experiment, and then we used exfoliant gel (NuPrep, Weaver, Aurora, USA) and alcohol

271 wipes (Uni-Wipe, Universal, Middlesex, UK) to prepare the electrode sites for

272 psychophysiological recordings. Next, we affixed the electrodes and checked the signals, and

273 then we described the task and instructions as detailed in the Design and Task section above.

274 Participants then completed a familiarization block, comprising 10 balls ( 5 red, 5 blue)

275 delivered in a random order. This allowed participants to become accustomed to the nature of

276 the task and allowed the experimenter to verify that participants understood the instructions

277 before the main experimental conditions.

278 After the familiarization block, participants were told that they would now complete

279 the same task for two more blocks of trials, containing 30 balls each. They were then asked to

280 complete the MRF-3, were reminded of the instructions, and then the 30-ball low-anxiety

281 condition commenced. The balls (15 red and 15 blue) were delivered in an order that was

282 randomized prior to the start of the experiment, and then fixed as the same random order for

283 all participants. The instructions were repeated half way through this condition. After the

284 final ball, participants were then given a 5-minute break.

285 After the break, the experimenter provided participants with additional instructions

286 designed to increase their anxiety, ahead of the final high-anxiety block. Specifically, we told

287 participants that their performance in this final block would be recorded as part of a 
competition and that we would display all scores on a television screen located in a busy indoor thoroughfare of the university. We told them that the winner of the competition (i.e., the highest number of points scored) would receive a $£ 100$ (approx. US\$125) prize, and that the second and third placed participants would receive prizes of $£ 30$ and $£ 20$, respectively.

Participants were then asked to complete the MRF-3, they were reminded of their

293 instructions, and then the 30-ball high-anxiety condition commenced. Once again, the balls

294 (15 red and 15 blue) were delivered in an order that was randomized prior to the start of the experiment, and then fixed as the same random order for all participants. Also consistent with the low-anxiety condition, we reminded participants of their instructions half way through the block. We decided that the low-anxiety condition should always precede the high-anxiety condition to minimize any anxiety carryover effect (cf. Hardy \& Hutchinson, 2007; Woodman et al., 2015). On completion of the high-anxiety block, the participants were thanked for their participation and fully debriefed. They were also informed that the researcher would be in touch on completion of data collection if they had won a cash prize. throughout the experiment. For our analyses, we calculated heart rate and heart rate variability from 30 seconds before the delivery of the first ball until 30 seconds after the delivery of the final ball in each condition. Ball delivery was identified by a switch affixed to the top of the chute, which triggered each time a ball was released, and was interfaced with the data-acquisition system to place an event marker in the Chart 7 software that was acquiring the psychophysiological recordings. To analyze muscle activity, we rectified the

309 electromyographic signal and then averaged activity across the trials for each condition

310 during the final second prior to ball release. We focused our analyses here because this was

311 the time when participants were in the ready position gripping the bat at the end of the chute 312 and preparing for the ball to be released. It was expected that any anxiety-induced increases 
313 in tension would manifest as an increase in grip force (and the associated forearm muscle

314 activity) during these final seconds of motor preparation (e.g., Smith et al., 2000). Due to excessive artifacts, the electrocardiogram and the electromyogram recordings were unscorable for twelve and six participants, respectively. Occasional missing data are reflected in the degrees of freedom reported in the results section.

Experiments 1-5) and a normal distribution was confirmed prior to analyses taking place. We conducted paired-samples $t$-tests to examine the effectiveness of our anxiety manipulation, and repeated measures ANOVA to examine the effects of anxiety on performance. The results of univariate tests are reported with the Greenhouse-Geisser correction procedure applied for analyses that violated the sphericity of variance assumption.

\section{Results}

Anxiety manipulation. Paired samples $t$-tests were conducted to analyse our selfreport and psychophysiological data. The results are summarized in Table 1 . They confirm the effectiveness of the anxiety manipulation. Specifically, we observed the expected increases in cognitive anxiety, somatic anxiety, muscle activity and heart rate, along with the expected decrease in r-MSSD, from the low- to the high-anxiety condition. significant Condition $\times$ Ball interaction, $F(1,52)=27.02, p<.001, \eta_{\mathrm{p}}^{2}=.34$. Subsequent paired sample $t$ tests revealed that participant scores comprised fewer target balls, $t(52)=$ $2.45, p=.018$, and more non-target balls, $t(52)=5.19, p<.001$, in the high-anxiety compared to the low-anxiety condition (see Figure 2). 


\section{Discussion}

The primary purpose of Experiment 1 was to examine Wegner's (1994) theory of ironic processes of mental control in an externally paced motor task. As hypothesized, participants caught significantly more of the forbidden non-target balls in the high-anxiety condition compared to the low-anxiety condition. This finding can be interpreted in support

344 of Wegner's (1994) theory. The increased feelings of worry in the high-anxiety condition could have consumed some of the conscious attentional resources required by the operating process, thereby compromising its effectiveness, and allowing the normally unconscious monitoring process to come to the fore. In addition to making more errors on the non-target balls, participants also made more errors on the target balls (i.e., caught fewer of them) when anxiety was increased. This pattern of worse performance on both target and non-target balls under anxiety represents a worst-case scenario in terms of limiting the number of points that each participant accrued. colleagues (2015) reported fewer darts hitting the target, and more darts hitting the to-beavoided zone, under the high-anxiety condition in their dart throwing study. However, due to the increased errors on the target balls, one could argue that our findings reflect general performance deterioration rather than a uniquely ironic breakdown during the high-anxiety condition. Specifically, it is possible that attentional resources were overloaded (e.g., Eysenck et al., 2007) causing an increase in all types of errors (e.g., target and non-target), rather than specifically priming ironic errors, as would be predicted by Wegner (1994). In Experiment 2 we introduced the third ball in an attempt to examine this possibility.

\section{Experiment 2}


364 relative merits of ironic processes versus an attentional overload account of performance

365 breakdown under anxiety. In brief, attention-based models of performance (e.g., Eysenck et

366 al., 2007) contend that we possess a limited attentional capacity, and that anxiety serves to

367 consume attentional resources. Consequently, increasing anxiety reduces goal-driven

368 attention, and can impair both processing efficiency and performance effectiveness (Eysenck

369 \& Calvo, 1992; Eysenck et al., 2007). While these theories have some overlap with ironic

370 processes theory, a key distinction is that anxiety-induced performance impairments

371 according to the former would be characterized by inefficient processing (e.g., slowed

372 responses) and a range of general errors, while the latter would predict that impairment would

373 be characterized by errors that are specifically ironic in nature (Wegner, 1994). Our

374 comparison of these competing theoretical accounts of performance was permitted by the

375 addition of a third ball, which had no instruction attached. Accordingly, we had a target ball,

376 a to-be-avoided non-target (ironic error) ball, and a non-target (non-error) ball. Based on the

377 view that stopping balls (i.e., inaction in the current task) represents an easier outcome than

378 programming an action in time-limited reactive tasks (cf. Land \& McLeod, 2000; Schmidt,

379 1980), we formulated alternate predictions about the non-target (non-error) ball. In support of

380 an attentional overload account of our findings (e.g., Eysenck et al., 2007), one would expect

381 that the number of non-target (non-error) balls stopped would increase from low- to high-

382 anxiety conditions. This would reflect the high-anxiety condition combining with any

383 confusion that may be caused by the third ball, to prompt attentional overload, slowing

384 processing down, and making the default inaction (i.e., stopping the ball) more likely.

385 Alternatively, in support of Wegner's (1994) ironic processes of mental control theory, we

386 hypothesized that there would be an anxiety-induced increase in the number of non-target

387 (ironic error) balls stopped, while the number of non-target (non-error) balls stopped would

388 remain unchanged. Such a finding would suggest that any anxiety-induced performance 
impairment can be specifically attributed to an increase in ironic errors, rather than a more general slowing down and increased likelihood of inaction under pressure.

Method

Participants. The sample comprised 40 participants ( 21 men, 19 women; $M_{\text {age }}=$ 22.65, $S D=6.3 ; 34$ right handed, 6 left handed). We recruited participants according to the same criteria as in Experiment 1. We excluded participants who had already taken part in Experiment 1 to ensure that all participants had no previous experience with the task. Informed consent obtained from all participants.

Design and Task. We adopted the same two-condition (low-anxiety; high-anxiety) within-subject design, and the same reactive motor task as detailed in Experiment 1, but with a modification. Specifically, we introduced a third ball color (yellow) and told participants "every ball you stop will go into a prize bucket, the red ball will score you plus five points and the blue ball will score you minus five points, obviously you should be very careful not the stop blue balls! Please try to score as many points as possible." No instruction or point value was attached to the third ball color. These instructions were designed to create a target ball, a non-target (ironic error) ball, and a non-target (non-error) ball. In the above example, the target ball is red, the non-target (ironic error) ball is blue and the non-target (non-error) ball is yellow. The instructions were modified between participants to ensure that each ball color had an equal turn at being the target, the non-target (ironic error), and the non-target (non-error) over the course of the experiment (i.e., fully counterbalanced). Participants reacted to 45 balls (15 blue, 15 red and 15 yellow) in both low-anxiety and high-anxiety conditions.

\section{Measures}


Performance. To measure performance we counted the number of the target, nontarget (ironic error) and non-target (non-error) balls that were stopped, in each condition. The same electronic buzzer system as described in Experiment 1 was used to determine whether a ball was successfully stopped. The range of scores was 0-15 for each ball, where the best score would be 15 for the target balls, and 0 for the non-target (ironic error) balls. The number of non-target (non-error) balls stopped had no bearing on the number of points accrued so was of little performance-related consequence to the participants.

Procedure. The procedure and anxiety manipulation were largely the same as balls ( 5 blue, 5 red, 5 yellow) instead of 10, and the anxiety conditions each contained 45 balls (15 blue, 15 red, 15 yellow) instead of 30. This increase in a number of balls reflects the addition of the third ball color in this experiment. The laboratory session lasted approximately 75 minutes.

Data Reduction and Statistical Analyses. Measures of heart rate, r-MSSD and muscle activity were computed from the continuous recordings using identical methods to those described in Experiment 1. Due to excessive artefacts, the electrocardiogram recordings were unscorable for six participants. Occasional missing data are reflected in the degrees of freedom reported in the results section. Statistical analyses were performed using the same strategy as described in Experiment 1.

\section{Results}

Anxiety manipulation. Paired samples $t$-tests were conducted to analyze the selfreport and psychophysiological data. The results confirm the effectiveness of the anxiety 436 manipulation. Specifically, we observed the expected significant increases in cognitive anxiety and somatic anxiety, and a non-significant trend for increases in muscle activity and 
438 heart rate, along with the expected significant decrease in, r-MSSD, from the low- to the 439 high-anxiety condition (see Table 2).

\section{** INSERT TABLE 2 ABOUT HERE **}

Performance. We performed a 2 (condition: low anxiety, high anxiety) $\times 3$ (ball: target, non-target ironic error, non-target non-error) fully repeated measures ANOVA to analyze performance. Results revealed no significant main effect for anxiety, $F(1,39)=1.80$, $p=.19, \eta_{\mathrm{p}}{ }^{2}=.04$, a significant main effect for ball $F(2,78)=34.54, p<.001, \eta_{\mathrm{p}}{ }^{2}=.47$, and a significant condition $\times$ ball interaction, $F(2,78)=10.03, p<.001, \eta_{\mathrm{p}}{ }^{2}=.20$. Follow-up paired sample $t$ tests indicated that participant scores comprised fewer target balls, $t(39)=$ $2.44, p=.019$ and more non-target (ironic error) balls, $t(39)=3.18, p<.001$, in the highanxiety compared to low-anxiety condition. The number of non-target (non-error) balls stopped did not change $t(39)=1.39, p=.17($ see Figure 3$)$.

\section{** INSERT FIGURE 3 ABOUT HERE **}

\section{Discussion}

The primary aim of Experiment 2 was to examine the relative merits of an ironic process versus an attentional overload account of performance breakdown under anxiety. In accord with Wegner's (1994) theory of ironic processes of mental control, we found that participants significantly stopped more non-target (ironic error) balls in the high-anxiety condition than in the low-anxiety condition, while the number of non-target (non-error) balls stopped was unchanged. These data favour an ironic processes explanation rather than an attentional overload explanation for the impaired performance under anxiety observed in

459 Experiments 1 and 2. Specifically, participants were more likely to do the thing they were 460 specifically instructed not to do (i.e., to stop the non-target ironic error balls). The number of non-target (non-error) balls stopped remained stable, which is important because such a pattern precludes a uniform attentional overload account of the results. That is, participants 
463

464

465

466

467

468

469

470

471

472

473

474

475

476

477

478

479

480

481

482

483

484

485

486

were not simply uniformly slowed under anxiety. Having established support for Wegner's theory as an explanation for anxiety-induced performance impairments in reactive tasks, a logical next applied step is to focus on methods of reducing the likelihood of such errors. Those methods are the focus of Experiment 3.

\section{Experiment 3}

Presently, there are no studies that focus on instructional interventions designed to reduce the likelihood of ironic errors during motor tasks. Instructions that burden the monitoring process with a relatively more difficult search than the operator could achieve this goal. Importantly, in Experiments 1 and 2, we instructed participants to "be particularly careful not to stop" the non-target (ironic error) ball. In this case, the operating process would have been searching for features associated with not stopping (i.e., an action; to move the bat out of the way before the ball reached the end of the chute), while the monitor would have been searching for features associated with stopping (i.e., an inaction; holding the bat firm). Given that action requires more programming than inaction in time-limited reactive tasks (e.g., Land \& McLeod, 2000; Schmidt, 1980), we seemingly gave the monitoring process an easier search than we gave the operator in Experiments 1 and 2, maximizing the likelihood of ironic errors under anxiety. To reverse this in Experiment 3, we instructed participants to "be particularly careful not to let [the non-target (ironic error) balls] go." With this revised instruction, the operator should have a comparatively easy search for inaction (i.e., stopping) while the monitoring process has the more difficult search for features associated with an action (i.e., letting go). Accordingly, for our theoretically-driven argument to be supported, we hypothesized that the anxiety-induced increase in ironic errors observed in Experiment 1 and 2 would be absent in Experiment 3.

\section{Method}


Participants. The sample comprised 41 individuals ( 24 men, 17 women; $M_{\text {age }}=22.63$,

$S D=3.92 ; 39$ right handed, 2 left handed). We recruited participants according to the same

criteria as in Experiment 1. We excluded participants who had already taken part in

Experiments 1 or 2 to ensure that all participants had no previous experience with the task.

Design and Task. We adopted the same two-condition (low-anxiety; high-anxiety)

within-subject design, and the same reactive motor task as detailed in Experiment 2, but we changed the instruction. Specifically, we told participants "every ball you let go will go into a prize bucket, the red ball will score you plus five points and the blue ball will score you

minus five points, obviously you should be very careful not to let the blue balls go! Please try to score as many points as possible." As per Experiment 2, no instruction or point value was attached to the third ball color. Participants reacted to 45 balls ( 15 blue, 15 red and 15 yellow) in both low-anxiety and high-anxiety conditions.

\section{Measures}

Manipulation Check. We measured anxiety, cardiac activity and muscle activity using the same methods as described in Experiments 1 and 2.

Performance. To measure performance we counted the number of target, non-target

503

504

505

506 (ironic-error), and non-target (non-error) balls that were let go, in each condition. The same electronic buzzer system as described in Experiments 1 and 2 was used. However, this time participants were informed that the buzzer must sound continuously from the point at which the bat is removed, and must sound before the ball strikes the bat, for a let go to be deemed successful. Once again, the range of scores was 0-15 for each ball, where the best score would be 15 for the target balls, and 0 for the non-target (ironic error) balls.

Procedure. The procedure was identical to that reported in Experiment 2.

Data Reduction and Statistical Analyses. Heart rate, r-MSSD and muscle activity were determined in the same way as reported in Experiments 1 and 2. All files were useable 
512 in this experiment; hence, there were no missing data. Statistical analyses were performed

513 using the same strategy as described in Experiments 1 and 2.

$514 \quad$ Results

515 Anxiety Manipulation. Paired samples $t$-tests were conducted to analyse our self-

516 report and psychophysiological data. The results are summarised in Table 3. Once again, they

517 confirm the effectiveness of our anxiety manipulation.

Performance. We conducted a 2 (condition: low anxiety, high anxiety) $\times 3$ (ball: target, non-target ironic error, non-target non-error) fully repeated-measures ANOVA to analyze performance. Results revealed no significant main effect for anxiety, $F(1,40)=1.33$, $p=.25, \eta_{\mathrm{p}}{ }^{2}=.03$, a significant main effect for balls, $F(2,80)=50.08, p<.001, \eta_{\mathrm{p}}{ }^{2}=.55$, and no significant anxiety $\times$ ball interaction $F(2,80)=0.29, p=.75, \eta_{\mathrm{p}}^{2}=.01$. Participants let more target balls go than non-target (non-error) and non-target (ironic error) balls; the number of times these latter two balls were let go did not differ (see Figure 4). This reflects consistent and relatively good performance across both anxiety conditions.

\section{** INSERT FIGURE 4 ABOUT HERE **}

\section{Discussion}

Experiment 3 tested our theoretically-driven prediction that instructions which give the monitoring process a more difficult search than the operator may reduce the likelihood of ironic errors occurring. The results of Experiment 3 represent the first support for this hypothesis. Specifically, by instructing participants "not to let [the non-target (ironic error) balls] go", we provided the operating process with a comparatively easy search for inaction

534 (i.e., stopping) while the monitoring process had the more difficult search for features associated with an action (i.e., letting go). Results confirmed that there was no deterioration in performance and no increase in ironic errors during the high-anxiety condition. This is 
537 despite the anxiety manipulation being equal in strength to those that did impair performance

538 in Experiments 1 and 2. Accordingly, Experiment 3 provides the first evidence that

539 instructional interventions can reduce the incidence of anxiety-induced ironic performance

540 errors in reactive motor tasks. Although these results are encouraging, one could argue that

541 the data in support of our hypotheses that ironic errors occur during reactive motor tasks

542 (Experiment 2) and can be alleviated by instructional interventions (Experiment 3) would be

543 more compelling had the non-target (non-error) ball used in these experiments been a non-

544 target (error) ball. Specifically, we could have attached a negative consequence to the third

545 ball, but of less severity than the negative consequence already attached to the ironic error

546 ball. Doing so would have given participants a clear target ball and two forms of error balls,

547 the severe "ironic error" ball, and a less severe "other error" ball. Compelling support for

548 Wegner's theory would be revealed if anxiety increases errors on the "ironic error" ball only

549 in this dual error configuration. This more stringent design was adopted in Experiment 4.

\section{Experiment 4}

The aim of Experiment 4 was to replicate the findings of Experiment 2 with a new sample to increase reliability and methodological rigor. The latter aim was permitted by the addition of a point value for the third ball. The purpose in Experiment 4 was to differentiate ironic from non-ironic error by clearly establishing two error balls. To do so, we introduced a new scoring system, awarding plus and minus five points for the target ball, and the nontarget (ironic error) ball, respectively, and minus two points for the non-target (other error) ball. With this revised scoring system, in support of Wegner's (1994) ironic processes of mental control theory and in accord with Experiment 2, we hypothesized that there would be an anxiety-induced increase in the number of non-target (ironic error) balls stopped, while the number of non-target (other error) balls stopped should remain unchanged.

\section{$561 \quad$ Method}


Participants. The sample comprised 24 individuals $\left(17\right.$ men, 7 women; $M_{\text {age }}=25.58$,

$S D=4.52 ; 20$ right handed, 4 left handed). We excluded participants who had already taken part in previous experiments of this study to ensure that all participants had no previous experience with the task.

Design and Task. We adopted the same two-condition (low-anxiety; high-anxiety) within-subject design, and the same reactive motor task as detailed in Experiments 1,2 and 3 but with a modification. Specifically, we told participants "every ball you stop will go into a prize bucket, the red ball will score you plus five points, the yellow ball will score you minus two points, and the blue ball will score you minus five points. Obviously you should be very careful not to stop the blue balls! Please try to score as many points as possible." These instructions were designed to create a target ball, a non-target (ironic error) ball, and a nontarget (other-error) ball. In the above example, the target ball is red, the non-target (ironic error) ball is blue and the non-target (other-error) ball is yellow. The instructions were modified between participants to ensure that each ball color had an equal turn at being the target, the non-target (ironic error), and the non-target (non-error) over the course of the experiment (i.e., fully counterbalanced). Participants reacted to 45 balls (15 blue, 15 red and 15 yellow) in both low-anxiety and high-anxiety conditions.

\section{Measures}

Manipulation Check. We measured anxiety, cardiac activity and muscle activity using the same methods as described in Experiments 1, 2 and 3.

Performance. To measure performance we counted the number of target, non-target (ironic-error), and non-target (other-error) balls that were stopped, in each condition. The same electronic buzzer system as described in Experiments 1,2 and 3 was used to determine whether a ball was successfully stopped. The range of scores was 0-15 for each ball, where 
586 the best score would be 15 for the target balls, and 0 for the non-target (ironic error) and the 587 non-target (other error) balls.

588 Procedure. The procedure was identical to that reported in Experiments 1, 2 and 3.

Data Reduction and Statistical Analyses. Heart rate, r-MSSD and muscle activity were determined in the same way as reported in Experiments 1, 2 and 3. Due to excessive artifacts, the electrocardiogram and the electromyogram recordings were unscorable for four and two participants, respectively. Occasional missing data are reflected in the degrees of freedom reported in the results section. Statistical analyses were performed using the same strategy as described in Experiments 1, 2 and 3.

\section{Results}

Anxiety Manipulation. Paired samples $t$-tests were conducted to analyse our selfreport and psychophysiological data. The results are summarised in Table 4. They again endorse the effectiveness of our anxiety manipulation with all variables changing in the expected direction. All the changes were statistically significant with the exception of muscle activity.

Performance. We conducted a 2 (condition: low anxiety, high anxiety) $\times 3$ (ball: target, non-target ironic error, non-target other-error) fully repeated-measures ANOVA.

604 Results revealed no significant main effect for anxiety $F(1,23)=.44, \mathrm{p}=.51, \eta_{\mathrm{p}}{ }^{2}=.01$, a 605 significant effect for balls, $F(2,46)=41.26, p<.001, \eta_{\mathrm{p}}{ }^{2}=.64$, and a significant anxiety $\times$ 606 ball interaction $F(2,46)=10.32, p=.001, \eta_{\mathrm{p}}{ }^{2}=.31, \varepsilon=.68$. Follow-up paired sample $t$ tests

607 indicated that participant scores comprised fewer target balls, $t(23)=2.65, p=.01$, and more 608 non-target (ironic error) balls, $t(23)=3.55, p<.001$, in the high-anxiety compared to low609 anxiety condition. The number of non-target (other-error) balls stopped did not change $t(23)$ $610=1.30, p=.20($ see Figure 5$)$ 


\section{Discussion}

613 The primary aim of Experiment 4 was to replicate the findings of Experiment 2 to

614 increase the reliability of our conclusions, as the replication would give a greater confidence

615 in the results and thus better support for Wegner's (1994) theory of ironic processes. We also

616 sought to increase methodological rigor from Experiment 2 by revising the task instructions

617 in order to clearly establish two error balls, and test whether anxiety elicited an increase in

618 errors on the severe "ironic error" balls only.

619 Results from Experiment 4 provide support for the results of Experiment 2 and

620 therefore Wegner's (1994) theory of ironic processes of mental control. In Experiment 4,

621 participants significantly stopped more non-target (ironic error) balls in the high-anxiety

622 condition compared to the low-anxiety condition. Importantly, the number of non-target

623 (other-error) balls stopped was unchanged across anxiety conditions. Thus, Experiment 4 was

624 able to differentiate ironic from non-ironic error and thereby add more compelling support for

625 the conclusion that anxiety can elicit a specific increase in ironic errors during reactive motor

626 tasks. We have already articulated that instructional interventions could reduce susceptibility

627 to these errors in Experiment 3, but to add further confidence to this conclusion, a next

628 logical step would be to test the effectiveness of the instructions used in Experiment 3, with

629 the dual-error scoring system used in Experiment 4. This was our aim in Experiment 5.

630

631

632

633

634

635

\section{Experiment 5}

The purpose of our final experiment was to replicate the findings from Experiment 3 in order to support our theoretically driven argument for instructional interventions to reduce the likelihood of ironic performance errors during reactive tasks. In that experiment we argued that instructions that load the monitoring process with a relatively more difficult search than the operator should help reduce the likelihood of specifically ironic errors. 
636 However, we concede that in Experiment 3 we only had one obvious error ball (i.e., ironic

637 error ball, minus five points). In Experiment 4 we modified our scoring system to establish 638 two types of error (ironic error, minus five points; and other error, minus two points). We

639 adopted this dual-error scoring system in Experiment 5. If our instructional intervention (i.e., 640 giving the monitor a more difficult task) really does help alleviate specifically ironic errors, 641 we hypothesized that the anxiety-induced increase in ironic errors that we observed in 642 Experiment 4 should be absent in Experiment 5.

643 Method

644 Participants. The sample comprised 23 individuals $\left(16\right.$ men, 7 women; $M_{\text {age }}=23.43$, $645 S D=3.62 ; 23$ right handed). We recruited participants according to the same criteria as in 646 Experiment 1. We excluded participants who had already taken part in Experiments 1, 2, 3 647 and 4 to ensure that all participants had no previous experience with the task.

648 Design and Task. We adopted the same two-condition (low-anxiety; high-anxiety) 649 within-subject design, and the same reactive motor task as detailed in Experiments 1, 2, 3 and 6504 but we modified the instruction. Specifically, we told participants "every ball you let go 651 will go into a prize bucket, the red ball will score you plus five points, the yellow ball will 652 score you minus two points, and the blue ball will score you minus five points. Obviously, 653 you should be very careful not to let the blue balls go! Please try to score as many points as 654 possible." Participants reacted to 45 balls (15 blue, 15 red and 15 yellow) in both low-anxiety 655 and high-anxiety conditions.

\section{Measures}

Manipulation Check. We measured anxiety, cardiac activity and muscle activity using the same methods as described in Experiments 1, 2, 3 and 4. 
661 electronic buzzer system as described in Experiments 1, 2, 3 and 4 was used. However, this

662 time participants were informed that the buzzer must sound continuously from the point at 663 which the bat is removed, and must sound before the ball strikes the bat, for a let go to be 664 deemed successful. Once again, the range of scores was 0-15 for each ball, where the best 665 score would be 15 for the target balls, and 0 for the non-target (ironic error) and non-target 666 (other error) balls.

667 Procedure. The procedure was identical to that reported in Experiment 4. Data Reduction and Statistical Analyses. Heart rate, r-MSSD and muscle activity were determined in the same way as reported in Experiments 1, 2, 3 and 4. Due to excessive artifacts, the electrocardiogram and the electromyogram recordings were unscorable for three and two participants, respectively. Occasional missing data are reflected in the degrees of 672 freedom reported in the results section. Statistical analyses were performed using the same strategy as described in Experiments 1, 2, 3 and 4.

Results

Anxiety Manipulation. Paired samples $t$-tests were conducted to analyse our selfreport and psychophysiological data. The results are summarised in Table 5. They again endorse the effectiveness of our anxiety manipulation with all variables changing in the expected direction. All changes were significant with the exception of muscle activity. ** INSERT TABLE 5 ABOUT HERE ** target, non-target ironic error, non-target non-error) fully repeated-measures ANOVA to analyze performance. Results revealed no significant main effect for anxiety, $F(1,22)=.12$, $p=.72, \eta_{\mathrm{p}}^{2}=.006$, a significant main effect for ball, $F(2,44)=38.87, p<.001, \eta_{\mathrm{p}}{ }^{2}=.63, \varepsilon=$ .69 , and no significant anxiety $\times$ ball interaction $F(2,44)=1.71, p=.19, \eta_{\mathrm{p}}^{2}=.07$. 
686 balls; the number of times these latter two balls were let go did not differ (see Figure 6). This

687 reflects consistent and relatively good performance across both anxiety conditions since the instructions were changed from Experiment 4 to Experiment 5.

\section{Discussion}

692 provide more compelling evidence that instructional interventions can mitigate against

693 anxiety-induced increases in specifically ironic performance errors. Results confirmed no

694 deterioration in performance and no increase in ironic errors during the high-anxiety condition. The findings of Experiments 3 and 5 thus supported our theoretically driven argument that burdening the monitor with a relatively more difficult search than the operator can prevent ironic errors. This represents the first support for instructional interventions to reduce ironic errors during reactive motor performance.

\section{General Discussion}

We conducted five experiments to address two limitations from the meagre extant literature examining Wegner's (1994) ironic processes of mental control in a performance setting. Specifically, we provide the first examination of ironic effects theory in an externally paced task under low- and high-anxiety conditions. Moreover, we report the first manipulation of task instruction designed to reduce the incidence of ironic performance errors.

In support of Wegner's (1994) theory, in Experiment 1, results demonstrate that participants made significantly more ironic errors when anxious. To our knowledge, this is the first evidence to support ironic processes theory as an explanation for performance breakdown under anxiety during reactive motor tasks. The results of Experiments 2 and 4 
711 additional type of error (Experiment 4) - revealed that any ironic performance errors were

712 unlikely to be accounted for simply by an indiscriminate anxiety-induced performance

713 decline (Woodman et al., 2015). Taken together, the results of these three experiments

714 suggest that instructions that prime the monitoring process with an easier search than the

715 operating process increase the prevalence of ironic errors. This is due to anxiety increasing

716 strain on our limited attentional capacity, preventing actions being programmed fast enough

717 to stop the forbidden error from occurring. Time-pressure concerns are particularly relevant

718 to reactive motor tasks. For instance, in the present experiments, participants had just $450 \mathrm{~ms}$

719 for their action to be programmed in order for them to successfully get out of the non-target

720 ironic error ball's path. With anxiety increasing the burden on the limited attentional system

721 during the high-anxiety condition, successful operating process performance was more

722 difficult to accomplish in the available time, and hence the monitor was more likely to come 723 to the fore.

724 Crucially, the results of Experiments 3 and 5 offer a solution to the ironic performance

725 problem. Specifically, by reframing task instruction in order to burden the monitoring process

726 with the more time-intensive action-based search, the anxiety-induced increase in ironic

727 errors observed in Experiments 1, 2 and 4 was eradicated in Experiments 3 and 5.

728 Collectively, these results represent the first evidence to support Wegner's (1994) ironic processes theory in reactive motor tasks, and the first to offer a practical and theoretically-

730 driven solution to limit the troublesome ironic error. The key applied implication of our

731 finding is that the instructions we issue to ourselves and to others should be framed to ensure

732 that the operating process always has an easier search than the monitor. For example,

733 Gorgulu and Woodman (2016) argued that coaches should tell their athletes what to do (e.g.,

734 strike the soccer ball into the net) rather than what to avoid (e.g., don't hit the post). The

735 current data support this recommendation and indicate that this is equally important for 
reactive tasks where movement decisions have to be made under time pressure. The current

737 data can also be interpreted to endorse holistic process goals as a way for performers to

738

739

740

741

742

743

744

745

746

747

748

749

750

751

752

753

754

755

756

757 support their operating process and promote successful motor performance. Holistic process goals encompass the key elements of a movement in a single phrase (e.g., "smooth", when applied to a golf putt; Mullen, Jones, Oliver \& Hardy, 2016) and thereby satisfy the need for an instruction of what do rather than what to avoid. Further, holistic process goals have been found to reduce anxiety (Kingston \& Hardy, 1997), which should reduce the likelihood of the monitoring process coming to the fore (Woodman et al., 2015). Moreover, when used by a sample of experienced athletes, holistic process goals such as "reach" and "drive" were associated with superior performance (e.g., less errors) during high-anxiety conditions (Mullen \& Hardy, 2010). Thus, we recommend that performers are issued with a clear and simple positive instruction (e.g., holistic process goals), to limit their susceptibility to ironic errors in sport. It would be interesting for future research to empirically examine this recommendation by testing the effects of holistic process goals on the incidence of specifically counter-intentional errors in the field (e.g., real-life sport).

\section{Limitations and Future Directions}

Although our results are highly consistent across studies, they should be interpreted in light of some limitations. First, we adopted a fixed condition order (i.e., low-anxiety condition; high-anxiety condition). This reduced the likelihood of anxiety carryover effects (Woodman et al., 2015), but provided an opportunity for learning effects. Specifically, participants may have been advantaged in the high-anxiety condition compared to the lowanxiety condition due to greater task familiarity / practice. Our data argue against the presence of learning effects, since performance was consistently worse in the high-anxiety condition. Nonetheless, it would be interesting for future research to re-examine our findings using well-learned tasks / expert populations to mitigate the risk of learning effects. For 
761 instance, testing the theory with expert sport performers and ecologically valid reactive sport

762 tasks would help increase the generalizability and utility of our conclusions (Henrich, Heine,

763 \& Norenzayan, 2010).

764 Second, future studies examining the merits of attentional models of performance

765 such as ironic processes theory would do well to employ techniques to measure attention. For

766 example, probe reaction time could be assessed during performance to provide an insight into

767 the attentional load that participants are experiencing (Lam, Masters \& Maxwell, 2010). Such

768 research has the potential to provide even more compelling evidence that anxiety-induced

769 performance breakdown is attributable to worry consuming our limited attentional resources

770 and leaving insufficient space for effective goal-driven (e.g., operating process) control, as

771 predicted by Wegner's (1994) theory.

772 Conclusion

773 In conclusion, our findings provide the first support for Wegner's ironic effects theory

774 in an externally-paced task. Moreover, we offer a practical instruction-based solution that can

775 reduce susceptibility to ironic errors and instead help individuals to thrive under pressure.

776 Specifically, performers and practitioners should be educated about ironic effects theory, and

777 encouraged to frame instructions in a way that burdens the monitoring process with the more

778 difficult task.

779

780

781

782

783

784

785 


\section{References}

787

788

789

790

791

792

793

794

795

796

797

798

799

800

801

802

803

804

805

806

807

808

809

Barlow, M., Woodman, T., Gorgulu, R., \& Voyzey, R. (2016). Ironic effects of performance are worse for neurotics. Psychology of Sport and Exercise, 24, 27-37. doi:10,1016/j.psychsport.2015.12.005

Cohen, J. (1992). A power primer. Psychological Bulletin, 112, 155-159. doi:10.1037/0033$\underline{2909.112 .1 .155}$

Cooke, A., Kavussanu, M., McIntyre, D., \& Ring, C. (2010). Psychological, muscular and kinematic factors mediate performance under pressure. Psychophysiology, 47, 11091118. doi:10.1111/j.1469-8986.2010.01021.x

Dugdale, J.R., \& Eklund, R.C. (2003). Ironic processing and static balance performance in high-expertise performers. Research Quarterly for Exercise and Sport, 74, 348-352. doi:10.1080/02701367.2003.10609102

Eysenck, M. W., \& Calvo, M. G. (1992). Anxiety and performance: The processing efficiency theory. Cognition and Emotion, 6, 409-434. $\underline{\text { doi: } 10.1080 / 02699939208409696}$

Eysenck, M. W., Derakshan, N., Santos, R., \& Calvo, M. G. (2007). Anxiety and cognitive performance: Attentional control theory. Emotion, 7, 336-353. doi:10.1037/1528$\underline{3542.7 .2 .336}$

Faul, F., Erdfelder, E., Lang, A.-G. \& Buchner, A. (2007). G*Power3: A flexible statistical power analysis program for the social, behavioural, and biomedical sciences. Behavior Research Methods, 39, 175-191.

Gray, R., Orn, A., \& Woodman, T. (2017). Ironic and reinvestment effects in baseball pitching: How information about an opponent can influence performance under pressure. Journal of Sport and Exercise Psychology. doi:10.1123/jsep.2016-0035 
810 Gorgulu, R. (2017). An Examination of the Precise Nature of Ironic Performance Breakdown. $811 \quad$ PhD thesis, Priyfsgol Bangor University.

812 Gorgulu, \& Woodman, (2016). This is what happens to footballers' brains when they miss 813 penalties. The Conversation, 25 June, 2016 retrieved on the 09.10.2018 from

814 https://theconversation.com/this-is-what-happens-to-footballers-brains-when-they-

$815 \quad$ miss-penalties-61598.

816 Hardy, L., \& Hutchinson, A. (2007). Effects of performance anxiety on effort and 817 performance in rock climbing: A test of processing efficiency theory. Anxiety, Stress, 818 and Coping, 20, 147-161. doi:10.1080/10615800701217035

819 Hardy, L., Woodman, T., \& Carrington, S. (2004). Is self-confidence a bias factor in higher 820 order catastrophe models? An exploratory analysis. Journal of Sport and Exercise $821 \quad$ Psychology, 26, 359-368. doi:10.1123/jsep.26.3.359

822 Henrich, J., Heine, S. J., \& Norenzayan, A. (2010). The weirdest people in the world? Behavioral and Brain Sciences, 33, 61-83. doi:10.1017/S0140525X0999152X

824 Janelle, C. M. (1999). Ironic processes in sport: Implications for the sport psychologist. The 825 Sport Psychologist, 13, 201-220. doi:10.1123/tsp.13.2.201

826 Krane, V. (1994). The Mental Readiness Form as a measure of competitive state anxiety. The 827 Sport Psychologist, 8, 189-202. doi:10.1123/tsp.8.2.189

828 Kingston, K., \& Hardy, L. (1997). Effects of different types of goals on processes that support performance. The Sport Psychologist, 11, 227-293. doi:10.1123/tsp.11.3.277

830 Lam, W. K., Masters, R. S., \& Maxwell, J. P. (2010). Cognitive demands of error processing 831 associated with preparation and execution of a motor skill. Consciousness and cognition, 19(4), 1058-1061. doi:10.1016/j.concog.2008.11.005

833 Land, M.F., \& McLeod, P. (2000). From eye movements to action: How batsmen hit the ball. Nature Neuroscience, 3, 1340-1345. doi:10.1038/81887 
835 Masters, R. S. W. (1992). Knowledge, knerves and know-how: The role of explicit versus implicit knowledge in the breakdown of a complex motor skill under pressure. British Journal of Psychology, 83, 343-358. doi:10.1111/j.2044-8295.1992.tb02446.x

Mateo, M., Blasco-Lafarga, C., Martinez-Navarro, I., Guzman, J. F., \& Zabala, M. (2012). Heart rate variability and pre-competitive anxiety in BMX discipline. European Journal of Applied Physiology, 112, 113-123. doi:10.1007/s00421-011-1962-8

Miller, O.J., \& Low, K. (2001). Motor processes in simple, Go/No-Go, and choice reaction time tasks: A psychophysiological analysis. Journal of Experimental Psychology: Human Perception and Performance, 27, 266-289. doi:10.1037//0096-1523.27.2.266

Mullen, \& Hardy, L. (2010). Conscious processing and the process goal paradox. Journal of Sport \& Exercise Psychology, 32, 275-297. doi:10.1123/jsep.32.3.275

Mullen, r., Jones, E. S., Oliver, S., \& Hardy, L. (2016). Anxiety and motor performance: More evidence for the effectiveness of holistic process goals as a solution to the process goal paradox. Psychology of Sport and Exercise, 27, 147-149. doi:10.1016/j.psychsport.2016.08.009

Murray, N.P., \& Raedeke, T.D. (2008). Hear rate variability as an indicator of precompetitive arousal. International Journal of Sport Psychology, 39, 346-355.

Oudejans, R.D., Binsch, O., \& Bakker, F.C. (2013). Negative instructions and choking under pressure in aiming at a far target. International Journal of Sport Psychology, 44, 294309. doi:10.1080/10615806.2010.481331

Robazza, C., Bortoli, L., \& Nougier, V. (2000). Performance emotions in an elite archer: A case study. Journal of Sport Behavior, 23, 144-163.

Schmidt, R.A. (1980). On the theoretical status of time in motor program representations. In G. E. Stelmach, \& J. Requin (Eds.), Tutorials in motor behavior (145-166). Amsterdam: North-Holland. doi:10.1016/S0166-4115(08)61943-3 
860 Smith, A.M., Malo, S.A., Laskowski, E.R., Sabick, M., Coonet, W.P., Finnie, S.B., Crews,

861

862

863

864

865

866

867

868

869

870

871

872

873

874

875

876

877

878

879

880

881

882

883

D.J., Eischen, J.J., Hay, I.D., Detling, N.J., \& Kaufman, K. (2000). A

multidisciplinary study of the 'yips' phenomenon in golf: an exploratory analysis. Sports Medicine, 30, 423-437. doi:10.2165/00007256-200030060-00004

Tarvainen, M.P., Niskanen, J.P., Lipponen, J.A., Ranta-aho, P.O., \& Karjalainen, P.A. Kubios HRV-Heart rate variability analysis software. Computer Methods and Programs in Biomedicine. 113, 210-220. doi:10.1016/j.cmpb.2013.07.024

Wegner, D. M. (1994). Ironic processes of mental control. Psychological Review, 101 , 34-52. doi:10.1037/0033-295X.101.1.34

Wegner, D.M., \& Erber, R. (1992). The Hyperaccessibility of Suppressed Thoughts. Journal of Personality and Social Psychology. 63, 903-912. doi:10.1037/0022-3514.63.6.903

Wegner, D. M., Ansfield, M. E., \& Pilloff, D. (1998). The putt and the pendulum: Ironic effects of the mental control of action. Psychological Science, 9, 196-199. doi:10.1111/1467-9280.00037

Woodman, T., Barlow, M., \& Gorgulu, R. (2015). Don't miss, don't miss, d'oh! Performance when anxious suffers specifically where least desired. The Sport Psychologist, 29, 213-223. doi:10.1123/tsp.2014-0114

Woodman, T., \& Davis, P. A. (2008). The role of repression in the incidence of ironic errors. The Sport Psychologist, 22, 184-197. doi:10.1123/tsp.22.2.183

Woodman, T., \& Hardy, L. (2003). The relative impact of cognitive anxiety and selfconfidence upon sports performance: a meta-analysis. Journal of Sports Sciences, 21, 443-457. doi:10.1080/0264041031000101809 


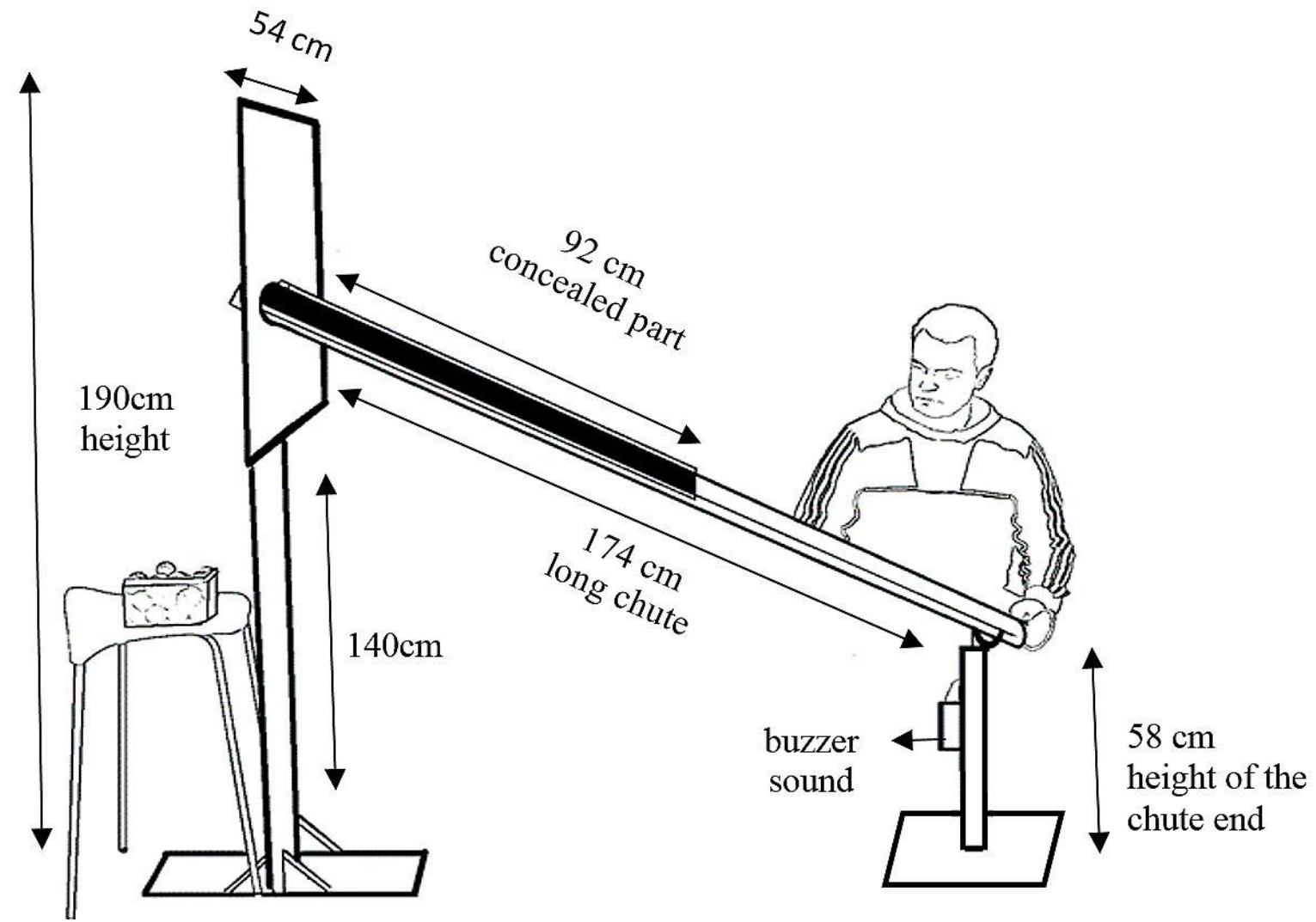

Figure 1. Illustration of the apparatus used. The buzzer system is described in the 


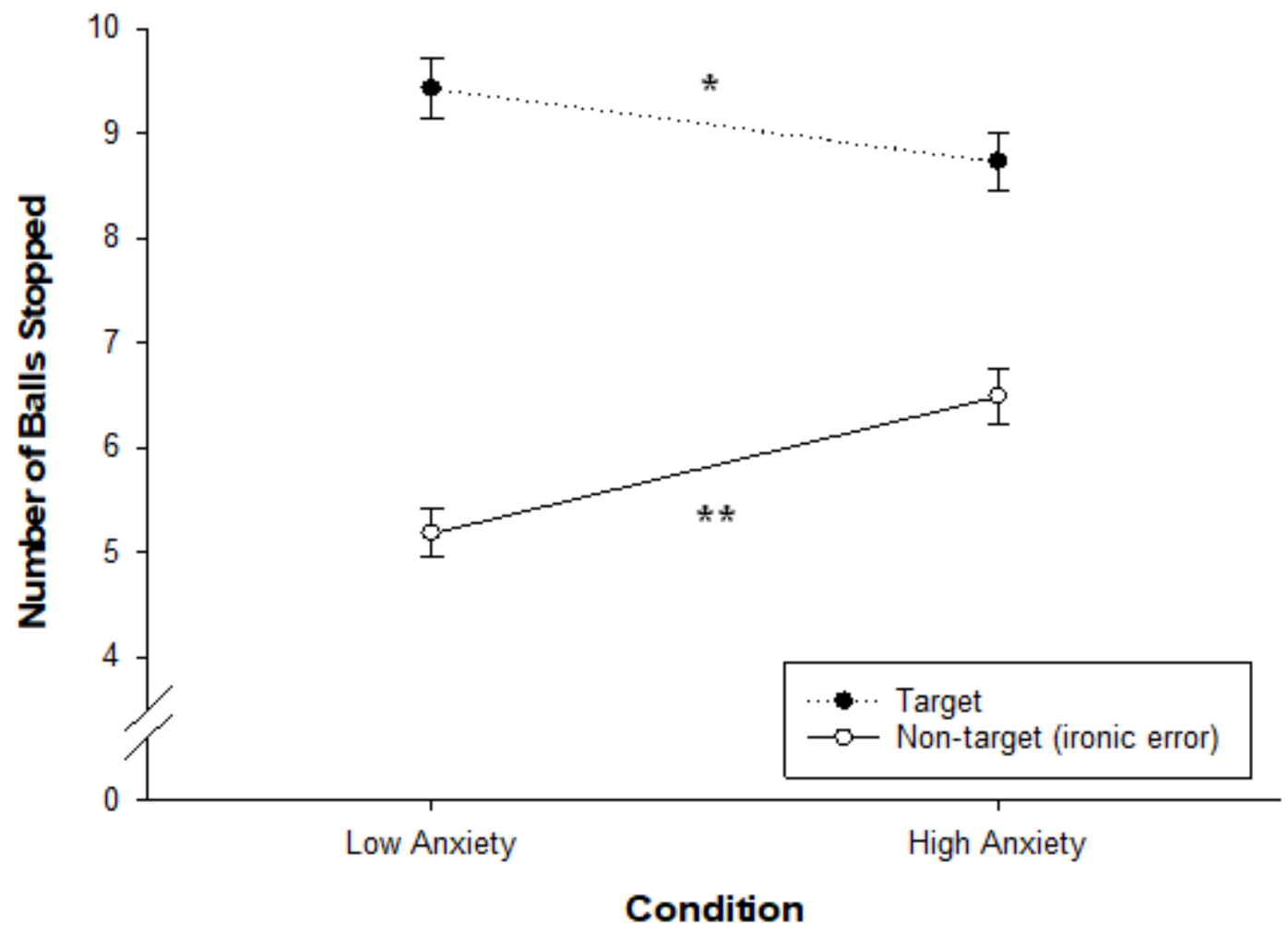

Figure 2. Mean number of target balls and non-target ironic error balls under low-anxiety and high-anxiety conditions in Experiment 1. Error bars indicate standard error of the means. $* p<.05, * * p<.01$. 




Figure 3. Mean number of target balls, non-target-non- error balls and non-target ironic error balls under low-anxiety and high-anxiety conditions for Experiment 2. Error bars indicate standard error of the means. $*=p<.05, * *=<.01$.

911

912

913

914

915

916

917

918

919

920

921

922 


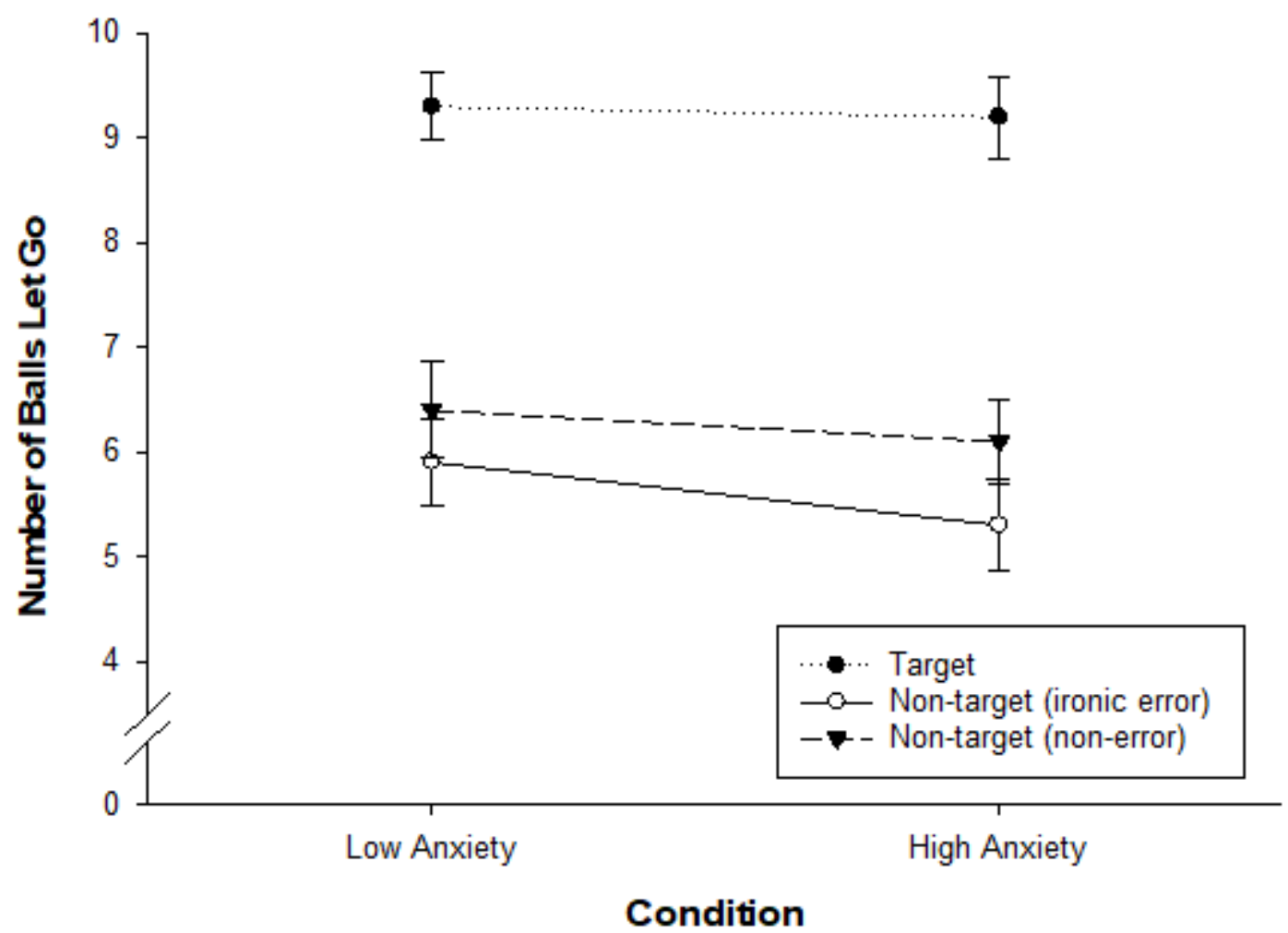

924

Condition

925 Figure 4. Mean number of target balls, non-target-non-error balls and non-target ironic error 926 balls under low-anxiety and high-anxiety conditions for Experiment 3. Error bars indicate 927 standard error of the means.

928

929

930

931

932

933

934

935

936

937

938

939 


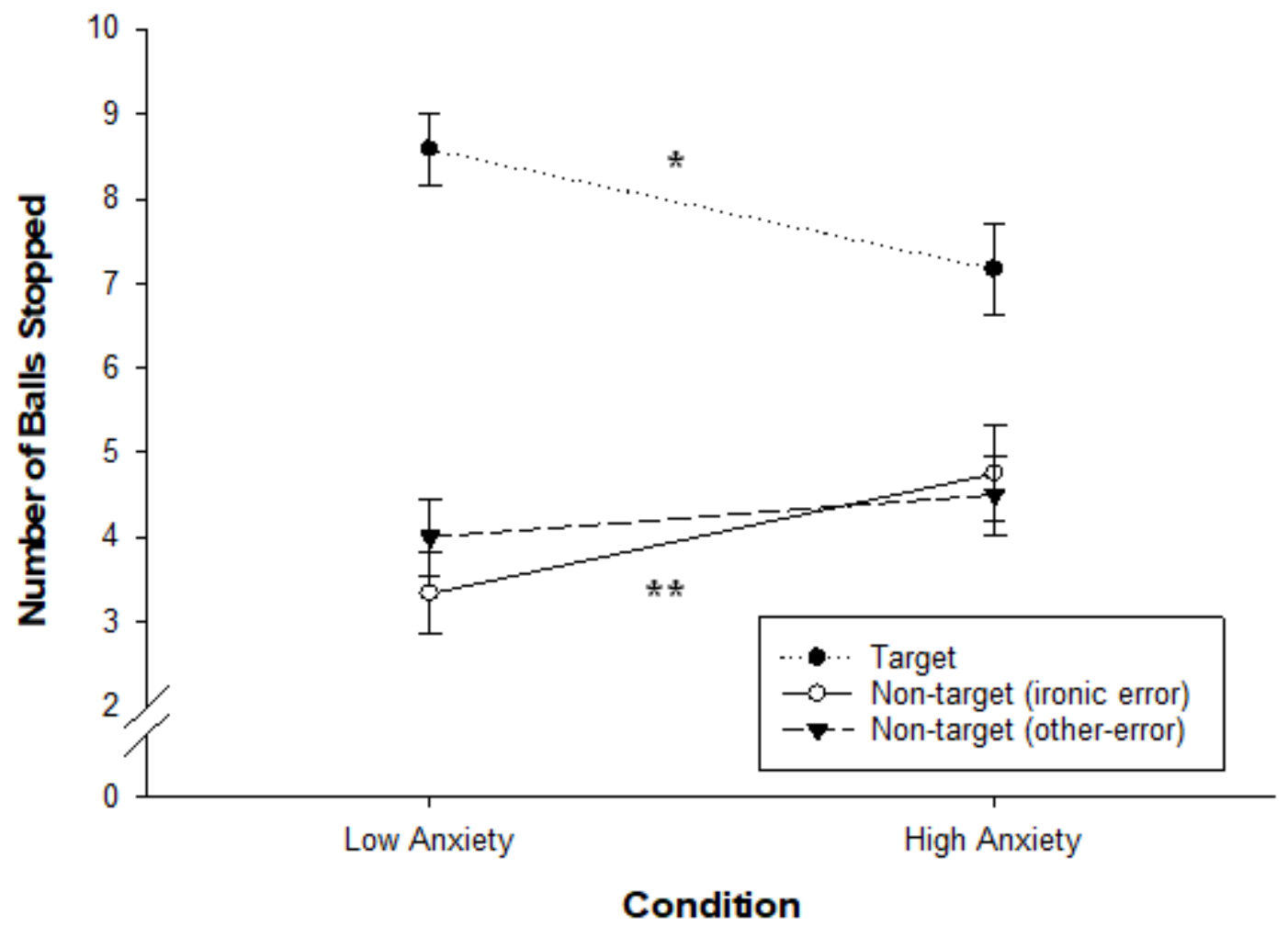

943 Figure 5. Mean number of target balls, non-target-other-error balls and non-target ironic 944 error balls under low-anxiety and high-anxiety conditions for Experiment 4 . Error bars 945 indicate standard error of the means. $*=p<.05, * *=<.01$. 




959

Condition

960 Figure 6. Mean number of target balls, non-target-other error balls and non-target ironic error 961 balls under low-anxiety and high-anxiety conditions for Experiment 5. Error bars indicate 962 standard error of the means.

963

964

965

966

967

968

969

970

971

972

973

974

975 
976

977 Table 1

978 Descriptive statistics confirming the effectiveness of the anxiety manipulation in Experiment $979 \quad 1$.

\begin{tabular}{lccc}
\hline \multirow{2}{*}{ Measure } & \multicolumn{3}{c}{ Condition } \\
\cline { 2 - 3 } & Low-Anxiety & High-Anxiety & \\
Cognitive anxiety & Mean (SD) & Mean (SD) & $t(52)$ \\
Somatic anxiety & $4.96(2.69)$ & $7.35(2.58)$ & $5.66^{* * *}$ \\
& $5.47(2.58)$ & $7.45(2.18)$ & $5.70^{* *}$ \\
Heart rate (bpm) & & & $t(41)$ \\
r-MSSD (ms) & $92.85(15.28)$ & $95.44(14.39)$ & $2.38^{*}$ \\
& $44.19(27.51)$ & $33.53(17.33)$ & $3.09^{* *}$ \\
Muscle activity $(\mu \mathrm{V})$ & & & $t(47)$ \\
\hline
\end{tabular}

980 Notes: $* p<.05, * * p<.01, * * * p<.001$.

981

982

983

984

985

986

987

988

989

990

991

992

993

994

995

996 
997

998 Table 2

999 Descriptive statistics confirming the effectiveness of the anxiety manipulation in Experiment 10002.

\begin{tabular}{lccc}
\hline \multirow{2}{*}{ Measure } & \multicolumn{3}{c}{ Condition } \\
\cline { 2 - 3 } & Low-Anxiety & High-Anxiety & \\
Cognitive anxiety & Mean (SD) & Mean (SD) & $t(39)$ \\
Somatic anxiety & $4.77(1.95)$ & $7.40(2.3)$ & $6.78^{* * *}$ \\
& $5.25(2.03)$ & $7.55(1.72)$ & $5.90^{* * *}$ \\
Heart rate (bpm) & & $t(34)$ \\
r-MSSD (ms) & $90.59(16.36)$ & $92.81(15.61)$ & $1.73^{\dagger}$ \\
& $59.29(33.54)$ & $47.84(26.02)$ & $3.04^{* *}$ \\
Muscle activity $(\mu \mathrm{V})$ & & & $t(39)$ \\
\hline
\end{tabular}

1001 Notes: $* * p<.01, * * * p<.001,{ }^{\dagger}=.09$.

1002

1003

1004

1005

1006

1007

1008

1009

1010

1011

1012

1013

1014

1015

1016

1017 
1018

1019 Table 3

1020 Descriptive statistics confirming the effectiveness of the anxiety manipulation in Experiment 10213.

\begin{tabular}{lccc}
\hline \multirow{2}{*}{ Measure } & \multicolumn{2}{c}{ Condition } & \\
\cline { 2 - 3 } & Low-Anxiety & High-Anxiety & \\
Cognitive anxiety & Mean (SD) & Mean (SD) & $t(40)$ \\
Somatic anxiety & $4.85(2.46)$ & $7.29(2.00)$ & $6.27^{* * *}$ \\
Heart rate $(\mathrm{bpm})$ & $5.14(2.44)$ & $7.46(2.00)$ & $6.49^{* * *}$ \\
r-MSSD $(\mathrm{ms})$ & $87.36(12.30)$ & $91.23(14.03)$ & $4.02^{* * *}$ \\
Muscle activity $(\mu \mathrm{V})$ & $50.35(23.82)$ & $41.43(18.92)$ & $3.63^{* * *}$ \\
\hline
\end{tabular}

1022

Notes: $* p<.05, * * * p<.001$.

1023

1024

1025

1026

1027

1028

1029

1030

1031

1032

1033

1034

1035

1036

1037

1038

1039 
1041 Table 4

1042 Descriptive statistics confirming the effectiveness of the anxiety manipulation in Experiment 10434.

\begin{tabular}{lccc}
\hline \multirow{2}{*}{ Measure } & \multicolumn{2}{c}{ Condition } & \\
\cline { 2 - 3 } & Low-Anxiety & High-Anxiety & \\
\cline { 2 - 3 } Cognitive anxiety & Mean (SD) & Mean (SD) & $t(23)$ \\
Somatic anxiety & $3.70(2.21)$ & $6.66(2.61)$ & $4.67 * * *$ \\
& $4.29(2.25)$ & $6.33(2.40)$ & $3.58^{* * *}$ \\
Heart rate $(\mathrm{bpm})$ & & & $t(19)$ \\
r-MSSD $(\mathrm{ms})$ & $85.69(17.37)$ & $90.46(20.03)$ & $3.51^{* * *}$ \\
& $56.30(32.96)$ & $47.33(33.10)$ & $2.84^{*}$ \\
Muscle activity $(\mu \mathrm{V})$ & & & $t(21)$ \\
\hline Notes: $p<.05, * * * p<.01 .28(9.06)$ & $22.09(9.62)$ & -.48 \\
\hline
\end{tabular}

1044 Notes: $* p<.05, * * * p<.001$.

1045

1046

1047

1048

1049

1050

1051

1052

1053

1054

1055

1056

1057

1058 
1060 Table 5

1061 Descriptive statistics confirming the effectiveness of the anxiety manipulation in Experiment 10625

\begin{tabular}{lccc}
\hline \multirow{2}{*}{ Measure } & \multicolumn{2}{c}{ Condition } & \\
\cline { 2 - 3 } & Low-Anxiety & High-Anxiety & \\
\hline Cognitive anxiety & $5.69(1.91)$ & $6.82(2.20)$ & $2.39^{*}$ \\
Somatic anxiety & $5.21(1.85)$ & $6.56(2.27)$ & $2.44^{*}$ \\
& & & $t(19)$ \\
Heart rate $(\mathrm{bpm})$ & $80.91(11.26)$ & $86.11(14.88)$ & $2.71^{*}$ \\
r-MSSD $(\mathrm{ms})$ & $49.92(24.94)$ & $39.48(21.75)$ & $2.52^{*}$ \\
Muscle activity $(\mu \mathrm{V})$ & & & $t(20)$ \\
\hline
\end{tabular}

1063 Notes: $* p<.05$. 